\title{
Naïve realism and unconscious perception: A reply to Berger and Nanay
}

\author{
Alfonso Anaya and Sam Clarke
}

Berger and Nanay (2017, henceforth B\&N) claim that naïve realism struggles to accommodate the existence of unconscious perception. Since there is said to be excellent evidence that perception of the same fundamental kind can occur, both consciously and unconsciously, this presents a problem for the view; it places a burden on the naïve realist to adequately address the phenomenon.

Can this burden be met? After considering, and rejecting, three possible routes to an affirmative answer, B\&N suggest a negative one. However, so far as we can see, all three routes considered remain perfectly plausible ways of addressing unconscious perception within a naïve realist framework. In each case, the burden then seems to remain with B\&N, or their sympathisers, to make a case against the naïve realist, rather than vice versa.

1. The first route considered by $B \& N$ would involve denying the existence of unconscious perception. If adequately defended, this would amount to showing that naïve realism is under no obligation to account for the phenomenon - a view that has recently been defended by Phillips (2016). However, despite acknowledging Phillips' proposal, B\&N simply state that it is one they are 'dubious' of. They do not actually engage with Phillips' arguments, something that would take them 'too far afield' (427).

On a charitable reading, this might be because $B \& N$ see a fundamental problem with the whole approach. They note that even if Phillips' rejection of the current empirical evidence for unconscious perception was sound, it would leave naïve realism 'hostage to forthcoming experimental results' (ibid.). For B\&N, this conflicts with naïve realism's claim to be a pretheoretical view of perception since it commits the view to empirical predictions that will be alien to the folk. But this is quite mistaken. Naïve realism, as a philosophical theory of perception, purports to provide a rich and sophisticated account of sense perception that vindicates an important and pretheoretically compelling claim: that mind independent objects feature as genuine constituents in perceptual experience. But this does not commit the naïve realist to all consequences of their view being equally amenable to common sense or pre-theoretical reflection (see Fish 2010: ch.6; Martin 2004: 39-40). Nor does it require the view to remain non-committal on the interpretation of complex experimental findings (see Campbell 2010). Rather, it leaves open the possibility that the view might make complex empirical predictions that offer to vindicate its (more intuitive) core 
commitments. So whether or not this route is ultimately tenable, there is nothing that $\mathrm{B} \& \mathrm{~N}$ say that undermines its plausibility.

2. A second route considered by B\&N would have the naïve realist accepting the existence of unconscious perception, but denying that the same relational analysis advanced to account for conscious perception should be advanced to account for unconscious perception. On this view, naïve realism would then be a theory of conscious perception, and conscious perception alone; unconscious perception would be an entirely separate issue. ${ }^{1}$

As $\mathrm{B} \& \mathrm{~N}$ note, this suggestion might be developed in two ways. On a transformational approach, naïve realists would say that something gets added to an unconscious perception that transforms it into a conscious experience. Meanwhile, on a non-transformational approach, conscious perception and unconscious perception would be viewed as ontologically different in kind (with naïve realism simply providing an account of the former). Both approaches are seen to suffer from a common failing, however. Namely, that it is hard to see how they mesh with existing empirically informed theories of consciousness. On a transformational account, the perceived problem is that it is unclear how a non-relational unconscious perceptual state could be transformed into a conscious perceptual relation on any such theory; for example, an Attentional Theory (like Prinz 2012), a Higher-Order Theory (like Lau and Rosenthal 2011), or a GlobalWorkspace Theory (like Dehaene et al. 2006). Meanwhile, on a nontransformational account, it is seen to be unclear what these existing theories of consciousness are actually theories of in the first place.

In neither case does the problem bite. On standard formulations, all of the above theories begin from an un-argued assumption that whatever it is that explains conscious perception, it must be something non-relational. For instance, Prinz's attentional account is motivated by the question 'what makes a representational brain-state conscious?' (2012: 79) and a relationalist answer to this question is not considered once. Despite this, Prinz is explicit that his theory is unable to explain all the relevant facts (2012: 289). In particular, he, like many opponents of naïve realism (Burge 2005: 46-47; Chalmers 1995), denies that his, or any of the other theories B\&N list, can explain why there is a phenomenal aspect to conscious perception. Consequently, it is not clear that these theories actually do provide an account of the relevant difference between conscious and unconscious perception that $\mathrm{B} \& \mathrm{~N}$ assume.

For the naïve realist, it is possible to trace this explanatory gap back to such theories' non-relational starting point (Fish 2008). This is not to commit the naive realist to the out-and-out rejection of the theories $\mathrm{B} \& \mathrm{~N}$ discuss,

1 This would be analogous to the naïve realist's disjunctive response to the argument from hallucination, where she/he denies that the correct account of veridical perception will carry over to cases of hallucination (Martin 2004). 
however. Such theories may well get things largely correct as an account of what goes on in the head when someone consciously perceives (providing an answer to B\&N's worry with non-transformationalism). For instance, where Prinz claims that perceptual experience correlates with information being made available to working-memory systems, the naïve realist seems free to claim that these inner processes play an important role in placing the perceiver in the acquaintance relation that is responsible for perceptual experience. But, if this is so, then there is no reason why a naïve realist account of the difference between conscious and unconscious perception requires the outright rejection of B\&N's listed theories (provided that they can be reformulated in line with the naïve realist's externalism in this way). To deny such a possibility without argument is, however, to assume the falsity of naïve realism from the get go - it is to beg the question. So, once again, the need for some such argument seems to leave the burden on B\&N's shoulders. ${ }^{2}$

3. A third route that is considered by $B \& N$ would have the naive realist accepting the existence of unconscious perception but assimilating it into their relational framework. On this approach, naïve realism would then provide a relational account of both conscious and unconscious perception. The challenge would simply be to account for the difference between the two.

According to $\mathrm{B} \& \mathrm{~N}$, it is here that things fall apart for this third suggestion. As they acknowledge, a natural way to account for the difference between conscious and unconscious perception on a naïve realist account of this kind would be by appeal to a difference in one of the relata that constitute the perceptual relation in question - that is to appeal to a difference in the objects of perception or the perceiving subject being related to these. But B\&N deny that this will work. For a start, they maintain that a difference in the object perceived could not explain the difference between conscious and unconscious perception, for the 'token object (and its properties) perceived consciously and unconsciously can be the same' (B\&N: 430).

Often, this is not as obvious as B\&N assume. Take a masked priming study where a stimulus (say, a red dot) flashes on a screen for an interval of time. Roughly speaking, if this interval of time is relatively short, the red dot will be perceived, but only unconsciously, whereas, if it is longer, the stimulus will be consciously perceived. Such cases provide a paradigmatic

$2 \quad \mathrm{~B} \& \mathrm{~N}$ do provide one further argument for the inadequacy of a non-transformational approach. They note a study by Cheesman and Merikle (1986) in which a consciously perceived stimulus is degraded until it can no longer be consciously perceived. This is said to provide evidence that one and the same state can be both conscious and unconscious, undermining the idea that there is an ontological distinction to be found. This requires careful handling, however. Not only does it conflict with Cheesman and Merikle's own assessment of the situation (357), it has been considered in recent critiques questioning the evidential basis for the existence of unconscious perception (Phillips 2016) and it can be seen to depend upon a controversial view of vagueness (see Williamson 1994). None of these complications are acknowledged by $\mathrm{B} \& \mathrm{~N}$. 
example of one and 'the same' object being perceived consciously and unconsciously on B\&N's story (426). But why say that the perceiver is being related to the same object in either case? We are only tempted to think of things in this way because we are invited to think of 'the red dot' in abstraction from the way its flashing on the screen occupies time. For once, we acknowledge the temporal difference between the two stimuli we have reason to doubt the identity claim being made. After all, the interval of time that the relevant events occupy is part of the experimental design and is manipulated so as to ensure that 'the object' in question can only be perceived one way or the other.

The naïve realist then has the potential to deny that, in such studies, all subjects perceive is $a$ red dot. Instead, they can claim that subjects are also perceptually aware of events involving the red dot, that is its flashing on the screen for a given period of time. ${ }^{3}$ Although these events all involve the red dot, they are not identical, for the interval of time they occupy is different. So, just as much empirical work into unconscious perception assumes there are various subjective thresholds below which objects can be perceived but only unconsciously, it is possible for the naïve realist to claim that unconsciously perceived events lacking in temporal extension may fall below a threshold of this sort. This would then be a relevant difference in the object of perception itself that could be appealed to by the naïve realist to explain when and why unconscious perception occurs under certain experimental conditions.

Admittedly, studies of this sort are not the only ones that have been seen to provide evidence of unconscious perception. For instance, in cases of blindsight a brain-damaged subject is said to perceive a stimulus unconsciously if it is presented in her blindfield, but not if it is presented elsewhere in her visual field. Such cases remain problematic for the naïve realist insofar as there need not be any corresponding difference in the object(s) perceived. This is not to say that the naïve realist lacks the resources needed to address the phenomenon, however. An obvious way in which this might be done would be by appealing to a difference in the manner that the relation of perceptual acquaintance gets instantiated.

This idea, that the relation of perceptual acquaintance can be instantiated in various ways and can be appealed to by the naïve realist to explain various aspects of the phenomenology of experience, has been widely acknowledged in the philosophical literature (see Allen 2013; French 2014, 2016; Pace 2007; Soteriou 2013: ch.5). To see why, consider a subject $S$ who is shortsighted in one eye and long-sighted in the other, such that an object at a

3 Note that this does not mean the naive realist needs to be committed to the idea that we only perceive events. The claim that we are perceptually aware of events is consistent with the claim that we also perceive objects and their properties. We would like to thank an anonymous referee for pressing us on this point. 
distance $d$ appears blurry through one eye, but crisp through the other. On a naïve realist story, this phenomenological difference may not be explained by some difference in the subject nor the object, for it is the same subject looking at the same object through either eye. However, it could be explained by appeal to the manner with which the subject is being psychologically related to the object of perception with either eye (blurrily versus clearly). But, if this is independently plausible (as many naïve realists will argue it is), then why would naïve realism lack the resources needed to accommodate the difference between conscious and unconscious perception, where both are viewed as relational phenomena? Just as $S$ can be related to a single object differently through either eye (blurrily versus non-blurrily), why can't the difference between a blindsighter consciously perceiving a cross in her conscious field and unconsciously perceiving it in her blindfield simply be seen to lie in the manner that the relation of awareness is instantiated in each case (consciously versus unconsciously)? ${ }^{4}$

Of course, this is not to provide a fully worked out theory of unconscious perception as a relational phenomenon - something that would be beyond the scope of this short paper. ${ }^{5}$ However, we do think it shows the burden to lie with $B \& N$ once again. In order to rule out this third route, a critic of naïve realism would have to show that perception of the same fundamental kind can occur both consciously and unconsciously, even when the objects perceived are identical and the manner with which the subject is related to them remains constant. At the very least, it is unclear that these conditions are met in masked priming studies or in cases of blindsight - that is the examples of unconscious perception discussed by B\&N.

4. B\&N do raise an important issue for the naïve realist: how to address the claimed existence of unconscious perception? What they fail to do is show

$4 \quad \mathrm{~B} \& \mathrm{~N}$ do consider a related suggestion: that naïve realists might appeal to a difference in some third relatum to explain the difference between conscious and unconscious perception. They suggest that such an appeal is empirically undermined by evidence that (according to them) would commit the naïve realist to holding that multiple relations of acquaintance with one and the same object can be instantiated simultaneously - something they take to be implausible (431). We believe there are various ways to respond to this worry for it is not obvious that the naïve realist really is committed to such a claim. However, the most straightforward response might be to simply point out that a naive realist can allow the possibility that multiple relations of acquaintance be instantiated towards the same object simultaneously, pace $\mathrm{B} \& \mathrm{~N}$, as when a single subject is perceptually related to a single object in different ways through different modalities. We thank [removed for anonymous review] for discussion of this issue.

5 There are various ways in which the idea might be developed, however. For instance, the manner in which we are related to items in unconscious perception might be elucidated along epistemic lines. So, just as seeing something blurrily leaves us in a worse position to form judgements about the items seen than if we were to see the same items clearly, unconscious perception might be said to leave us in a relatively poor position to form judgements about both the objects so-perceived and the perceptual episode itself-after all, we might not be able to know that we are undergoing the relevant perceptual episode. 
why this should be problematic for the view. In light of their critique, all three options considered remain perfectly plausible. So, far from undermining naïve realism, unconscious perception simply raises a question to be addressed by naïve realists in future work: which (if any) of the above approaches is most likely to provide an accurate account of the phenomenon in each of its purported incarnations? ${ }^{6}$

\author{
University of Warwick \\ Gibbet Hill Road, Coventry CV4 7AL, \\ Coventry, UK \\ alfonso.ws@gmail.com
}

University of Oxford

115a Southfield Road, Oxford OX4 1NY, UK clarkesam563@gmail.com

\title{
References
}

Allen, K. 2013. Blur. Philosophical Studies 162: 257-73.

Berger, J. and B. Nanay. 2017. Relationalism and unconscious perception. Analysis 76: 426-33.

Burge, T. 2005. Disjunctivism and perceptual psychology. Philosophical Topics 33: 1-78.

Campbell, J. 2010. Demonstrative reference, the relational view of experience, and the proximality principle. In New Essays on Singular Thought, ed. R. Jeshion, 191-212. Oxford: Oxford University Press.

Chalmers, D. 1995. The Conscious Mind. Oxford: Oxford University Press.

Cheesman, J. and M. Merikle. 1986. Distinguishing conscious from unconscious perceptual processes. Canadian Journal of Psychology 40: 343-67.

Dehaene, S., J.P. Changeux, L. Naccache, J. Sackura and C. Sergenta. 2006. Conscious, preconscious, and subliminal processing: a testable taxonomy. Trends in Cognitive Sciences 10: 204-11.

Fish, W. 2008. Relationalism and the problem of consciousness. Teorema: International Journal of Philosophy 28: 167-80.

Fish, W. 2010. Philosophy of Perception: A Contemporary Introduction. New York: Routledge.

French, C. 2014. Naive realist perspectives on seeing blurrily. Ratio (Special Issue: The Structure of Perceptual Experience) 27: 393-413.

French, C. 2016. Idiosyncratic perception. The Philosophical Quarterly 66: 391-99.

Lau, H. and D.M. Rosenthal. 2011. Empirical support for higher-order theories of conscious awareness. Trends in Cognitive Sciences 15: 365-73.

6 Both authors contributed equally to this work. They are grateful to Jacob Berger, Wesley Chai, Bence Nanay, Ian Phillips, Matthew Soteriou and two anonymous reviewers for helpful comments on earlier drafts of this paper. 
Martin, M. 2004. The limits of self-awareness. Philosophical Studies 120: 37-89.

Pace, M. 2007. Blurred vision and the transparency of experience. Pacific Philosophical Quarterly 88: 328-54.

Phillips, I. 2016. Consciousness and criterion: on Block's case for unconscious seeing. Philosophy and Phenomenological Research 93: 419-51.

Prinz, J.J. 2012. The Conscious Brain: How Attention Engenders Experience. Oxford: Oxford University Press.

Soteriou, M. 2013. The Mind's Construction. Oxford: Oxford University Press.

Williamson, T. 1994. Vagueness. London: Routledge. 


\begin{abstract}
In a recent paper, Berger and Nanay consider, and reject, three ways of addressing the phenomenon of unconscious perception within a naïve realist framework. Since these three approaches seem to exhaust the options open to naïve realists, and since there is said to be excellent evidence that perception of the same fundamental kind can occur, both consciously and unconsciously, this is seen to present a problem for the view. We take this opportunity to show that all three approaches considered remain perfectly plausible ways of addressing unconscious perception within a naïve realist framework. So far from undermining the credibility of naïve realism, Berger and Nanay simply draw our attention to an important question to be considered by naïve realists in future work. Namely, which of the approaches considered is most likely to provide an accurate account of unconscious perception in each of its purported incarnations?
\end{abstract}

Keywords: Naive Realism, Unconscious Perception, Blindsight 